\title{
Boundary Layer Chemical Vapour Synthesis of Self-Organised Ferromagnetically Filled Radial-Carbon-Nanotube Structures
}

\author{
Filippo S. Boi ${ }^{a, b}$, Rory M. Wilson ${ }^{c}$, Gavin Mountjoy ${ }^{d}$, Muhammad \\ ${ }_{5}$ Ibrar $^{a}$, Mark Baxendale*,a \\ DOI: 10.1039/b000000x [DO NOT ALTER/DELETE THIS TEXT]
}

\begin{abstract}
Boundary layer chemical vapour synthesis is a new technique that exploits random fluctuations in the viscous boundary layer between a laminar flow of pyrolysed 10 metallocene vapour and a rough substrate to yield ferromagnetically filled radial-carbonnanotube structures departing from a core agglomeration of spherical nanocystals individually encapsulated by graphitic shells. The fluctuations create the thermodynamic conditions for formation of the central agglomeration in the vapour which subsequently defines the spherically symmetric diffusion gradient that initiates the radial growth. The

15 radial growth is driven by the supply of vapour feedstock by local diffusion gradients created by endothermic graphitic-carbon formation at the vapour-facing tips of the individual nanotubes and is halted by contact with the isothermal substrate. The radial structures are the dominant product and the reaction conditions are self-sustaining. Ferrocene pyrolysis yields three common components in the nanowire encapsulated by

20 multiwall carbon nanotubes, $\mathrm{Fe}_{3} \mathrm{C}, \alpha-\mathrm{Fe}$, and $\gamma$-Fe. Magnetic tuning in this system can be achieved through the magnetocrystalline and shape anisotropies of the encapsulated nanowire. Here we demonstrate proof that alloying of the encapsulated nanowire is an additional approach to tuning of magnetic properties of these structures by synthesis of radial-carbon-nanotube structures with $\gamma$-FeNi encapsulated nanowires.
\end{abstract}

\section{Introduction}

Ferromagnetic transition-metal-based nanowires encapsulated by carbon nanotubes have a long history of investigation owing to a plethora of potential applications ${ }^{1-9}$.The carbon 30 nanotube serves to chemically passivate and minimise mechanical degradation of the central nanowire. The magnetic functionality of these structures can be tuned through the shape and magnetocrystalline anisotropies of the nanowire, which in turn can be controlled by process parameters ${ }^{10}$. These structures self-organise on smooth, inert substrates exposed to a steady-state vapour flow comprising the products of metallocene $\left(\mathrm{M}_{(}\left(\mathrm{C}_{5} \mathrm{H}_{5}\right)_{2}\right.$, where $\mathrm{M}$

35 is a transition metal) pyrolysis at high temperature in a conventional CVD reactor. The detail of the formation mechanism is controversial; descriptions usually evoke the same vapour-, liquid-, and solid-phase chemistry and catalysis at transition-metal surface models that underpin production methods for unfilled carbon nanotubes by catalytic $\mathrm{CVD}^{11-14}$. The elemental iron from the products of ferrocene pyrolysis $\left(\mathrm{Fe}+\mathrm{H}_{2}+\mathrm{CH}_{4}+\mathrm{C}_{5} \mathrm{H}_{6}+\ldots\right.$, ) forms 40 a particle on the inert substrate which then reacts with the local hydrocarbon environment. The carbon-to-metal ratio in this local environment is carbon-rich relative to those used in single-wall nanotube production therefore the outcome is growth of a multiwall carbon nanotube (MWCNT). The subsequent growth of the MWCNT and the filling of its central capillary by elemental iron or an iron-carbide is driven by supply of species from the

45 vapour either to the base of the structure or to the open tip, or both. This is an entirely selforganised production process. It is important to note that the nucleation of the MWCNT 
growth is heterogeneous, i.e. occurs at the iron-particle/substrate interface. The final reaction product is a closely-packed array of individual MWCNT-encapsulated singlecrystal nanowires oriented perpendicular to the substrate. The most commonly observed encapsulated crystal structures are $\mathrm{Fe}_{3} \mathrm{C}, \alpha-\mathrm{Fe}$, and $\gamma-\mathrm{Fe}^{1-9}$. The surprising observation of ${ }_{5} \gamma$-Fe, which is a high-temperature, high-pressure phase in bulk, has been attributed to frustration of a relaxation to $\alpha-\mathrm{Fe}$ due to confinement by the elastic MWCNT.

The landmark publication by Boi et al demonstrated vapour-phase, homogeneous nucleation of equivalent structures through use of intentionally roughened substrates to 10 produce powders of spherically symmetric, radial filled-carbon-nanotube structures departing from a central particle ${ }^{15}$, Figs.1,2.

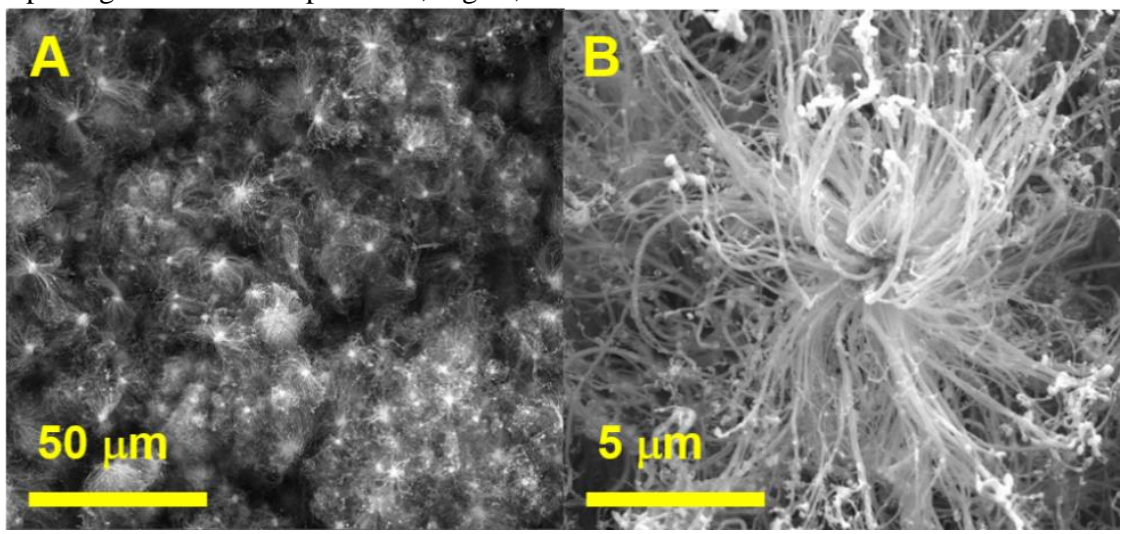

Fig.1 Scanning electron micrographs, A: an ensemble of radial structures comprising iron-based nanowires encapsulated by multiwall carbon nanotubes departing from a central particle deposited 15 on a roughened quartz substrate under and Ar/ferrocene vapour flow in a conventional horizontal CVD reactor at $990{ }^{\circ} \mathrm{C}$, and B: detail of an individual structure.
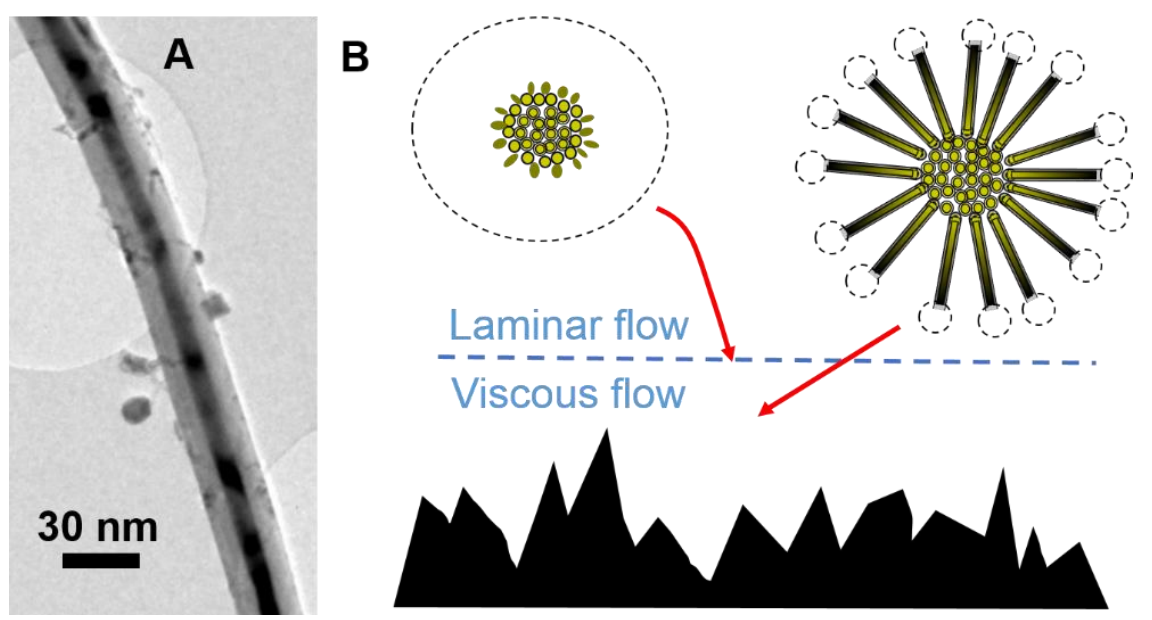

Fig.2 A: Transmission electron micrograph of a typical individual radial multiwall carbon nanotube, the nanowire is typically continuous for several micrometres $[\mathrm{X}]$. B: A schematic diagram depicting

20 the principles of boundary layer chemical vapour synthesis; the pyrolysed metallocene flow is horizontal over the roughened substrate (black); spherically encapsulated nanocrystals rapidly nucleate and agglomerate at the boundary between laminar and viscous flow (dotted black lines represent the symmetry of diffusion gradients); peripheral nanocrystals are elongated by supply of feedstock species from the incoming vapour, these nucleate the growth of the radial nanotubes; the 25 growth of the radial structure is driven by the diffusion gradient at the nanotube tips. 
Detailed analysis of the central particle revealed it to be an agglomeration of smaller $\mathrm{Fe}_{3} \mathrm{C}$ nanocrystals encapsulated by spherical graphitic-carbon shells so it is more correctly referred to as the core-agglomeration. The primary significance of this work was that the role of the roughened substrate was to intentionally introduce fluctuation in the flowing 5 vapour and in so doing create thermal pathways within the reactor capable of a reproducible yield of a single, dominant reaction product that nucleates and grows entirely in the vapour.

An early vapour-composition/product-morphology mapping in transition-metal/carbon 10 systems by Elliott et al identified the local vapour-phase carbon-to-metal ratio in a given thermal trajectory as the significant factor which determines the product composition/morphology ${ }^{16}$. Since the thermal trajectories in boundary layer chemical vapour synthesis are defined by fluctuation-induced nucleation and the carbon-to-metal ratio by the selection of decomposed molecule, we propose the method as a route to the

15 controlled production of transition-metal/carbon structures with unusual composition and morphologies.

Ferromagnetically filled MWCNTs have a wide range of potential applications owing to the ability to tune the magnetic properties through the control of composition, 20 magnetocrystalline- and shape-anisotropy of the encapsulated single-crystal nanowires: magnetic storage media and quantum disk fabrications (owing to the high coercivity displayed by single magnetic domain ferromagnetic systems); drug delivery and nanoscale containers for biomedical therapy, monitoring and diagnosis (these exploit the high mechanical strength and hysteretic dissipation in presence of a time varying magnetic

${ }_{25}$ field); magnetic force microscopy probes; nanocomposite magnetic filler particles; buckypaper; microwave absorption materials, and nanoscale inductors ${ }^{17-30}$. In addition some applications exploit the torque in a constant magnetic field, or the oscillatory motion in a time-varying magnetic field ${ }^{23,25}$.

30 The principle reasons for considering radial structures, rather than the counterpart produced by conventional CVD, for these applications are: i) the method of synthesis is conducive to bulk production, ii) the nanowires are continuous on the micrometre scale (at least one order of magnitude greater than can be achieved by conventional methods), and iii) the morphology facilitates ease of dispersion in polymeric matrices.

35

The filling nanotubes with $\mathrm{Fe}-\mathrm{Ni}$ or Co-Fe alloys has been recently shown to increase the degree to which these systems can be magnetically tuned, opening new ways of controlling the Curie temperature, coercivity, saturation magnetization, and facilitating the fabrication of nanotube-based spin-valve prototypes ${ }^{31-38}$. Much of this interest has focused on $\gamma$-FeNi 40 alloys. Sufficient control of the Fe content could allow tuning the Curie temperature to the ablation temperature for magnetic hyperthermia cancer therapy $\left(\sim 45^{0} \mathrm{C}\right)^{39,40}$. The central difficulty prohibiting the translation of prototypes to industrial production is the lack of achievable compositional and dimensional control with existing CVD methods. Ultimately, this poor control is a manifestation of the heterogeneous nucleation 45 (metal/substrate interaction) and natural fluctuation in steady-state diffusion gradients.

Here we demonstrate the principle of production of alloyed nanowire in radial structures by boundary layer chemical vapour synthesis. Radial $\gamma$-FeNi alloy-filled-MWCNTs were synthesised in vapour produced by the thermal decomposition of ferrocene and 50 nickelocene. Through X-ray diffraction, scanning electron microscopy, and transmission electron microscopy we obtain the composition and the morphology of these structures.

\section{Experimental procedure}




\subsection{Synthesis}

A mixed powder of $30 \mathrm{mg}$ of ferrocene and $70 \mathrm{mg}$ of nickelocene was sublimated using a coil preheater (maximum temperature $\sim 180{ }^{\circ} \mathrm{C}$ ) in a $12.5 \mathrm{ccm}$ argon flow upstream of a horizontal CVD reactor comprising a quartz tube (length: $2 \mathrm{~m}$, outer diameter: $22 \mathrm{~mm}$, ${ }_{5}$ inner diameter: $19 \mathrm{~mm}$, wall thickness: $1.5 \mathrm{~mm}$ ) positioned inside a one-zone electrical furnace with the isothermal reaction zone at $990{ }^{\circ} \mathrm{C}$. The roughened substrates $(100 \mu \mathrm{m}$ peak-to-valley fractal roughness) were placed in the isothermal reaction zone. The duration of the reaction was 4.5 minutes. The reactor was cooled to room temperature at the natural rate of the furnace.

10

\subsection{Characterisation}

Scanning electron microscopy (SEM) was performed using an FEI Inspect F microscope. X-ray diffraction (XRD) analyses were performed with both a Siemens D5000 and XpertPro diffractometers (both with $\mathrm{Cu} \mathrm{K}_{\alpha}$ source). The samples were prepared by evaporation 15 of the alcohol in which the structures were previously dispersed. The diffractograms were analysed using the ICSD chemical database cards for the commonly observed as products of the ferrocene and nickelocene pyrolysis. The Rietveld refinement method, which uses the least-squares approach to match a theoretical line profile to the diffractogram, was used to identify and estimate the relative abundances of the encapsulated phases from the area 20 enclosed by the diffraction peaks. The oxides $\mathrm{Fe}_{3} \mathrm{O}_{4}$ and $\mathrm{NiO}$ result from spontaneous oxidation of non-encapsulated iron or nickel when the sample is handled in air (confirmed by electron microscopy). Transmission electron microscopy (TEM) was performed by using a $200 \mathrm{kV}$ Jeol Jem 2010 with a $\mathrm{LaB}_{6}$ filament. The TEM samples were prepared by transferring the structures to carbon-coated copper grids. The magnetisation measurements 25 were performed at $5 \mathrm{~K}$ with a MPMS-7 magnetometer (Quantum Design) on powder extracted from the reactor.

\section{Results and discussion}

Scanning electron micrographs of the substrates extracted from the reactor revealed thick deposits comprising ensembles of individual radial structures, Figs.3,4. In some cases the

30 central core-agglomeration is elongated and flattened, relative to those observed in ferrocene-only syntheses, and the MWCNTs grow mainly from the flattened faces, Figs.4C,4D.

XRD analyses of the deposit revealed the presence of $\gamma$-FeNi and elemental Ni; Fig.5. The 35 relative abundance of the phases obtained from this data was $7.4 \% \gamma$-FeNi (space group Fm-3m), 16.2\% $\mathrm{Ni}$ (space group Fm-3m), 67.4\% C(1) (space group $\mathrm{P}_{3} / \mathrm{mmc}$ ), 3.4\% $\mathrm{Fe}_{3} \mathrm{O}_{4}$ (Fd-3mz), 3.0\% NiO (space group Fm-3m) and 2.6\% C(2) (space group P63/mmc). The presence of oxides is the result of the oxidation of traces of elemental metal on the exterior of the structures due to post-synthesis handling in air.

40

No evidence for presence of $\mathrm{Fe}_{3} \mathrm{C}$ and $\mathrm{Ni}_{3} \mathrm{C}$ phases was found. This is surprising since $\mathrm{Fe}_{3} \mathrm{C}$ and $\mathrm{Ni}_{3} \mathrm{C}$ are considered essential intermediates for MWCNT growth ${ }^{41-50}$. Previous reports of this synthesis using conventional solid- and liquid-source CVD do not comment on the absence of $\mathrm{Ni}_{3} \mathrm{C}$ and $\mathrm{Fe}_{3} \mathrm{C}$ in the final product nor attempt to describe the growth

${ }_{45}$ mechanism ${ }^{31-38}$. The absence of $\mathrm{Fe}_{3} \mathrm{C}$ and $\mathrm{Ni}_{3} \mathrm{C}$ diffraction peaks in Fig. 5 suggests that there is direct formation of $\mathrm{FeNi}$ alloys without the intermediate metal carbide formation, or MWCNT growth is driven by the carbon supply from an unstable carbide that decomposes that high rate.

4 | [journal], [year], [vol], 00-00 


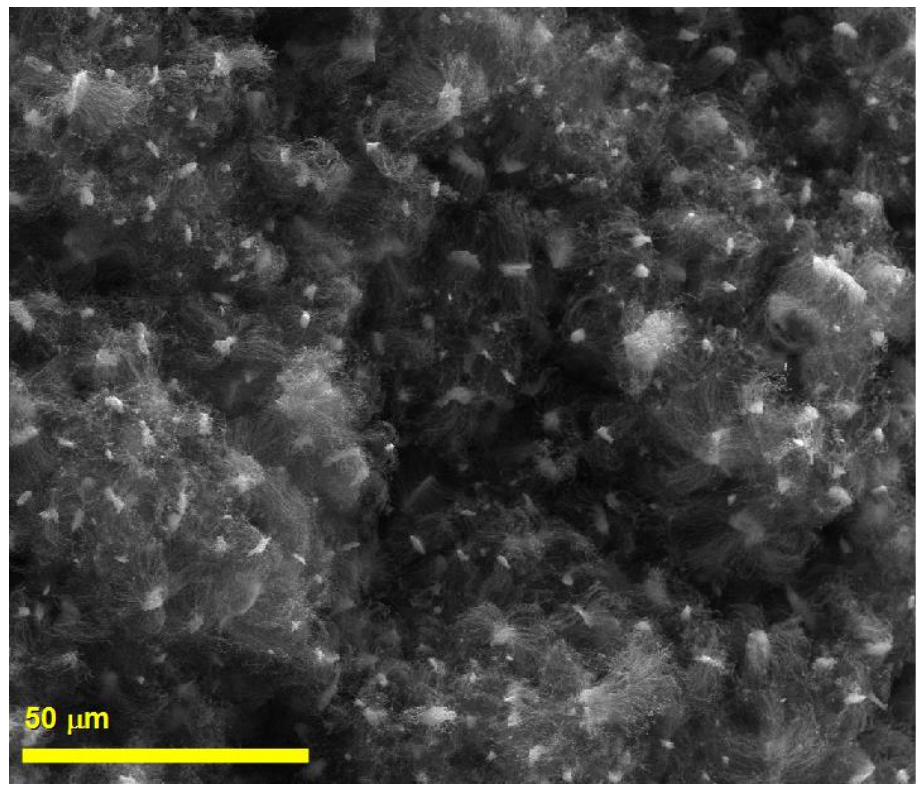

Fig.3 Scanning electron micrograph of an ensemble of the radial structures deposited on a roughened quartz substrate under and Ar/ferrocene-nickelocene vapour flow in a conventional horizontal CVD reactor at $990^{\circ} \mathrm{C}$,

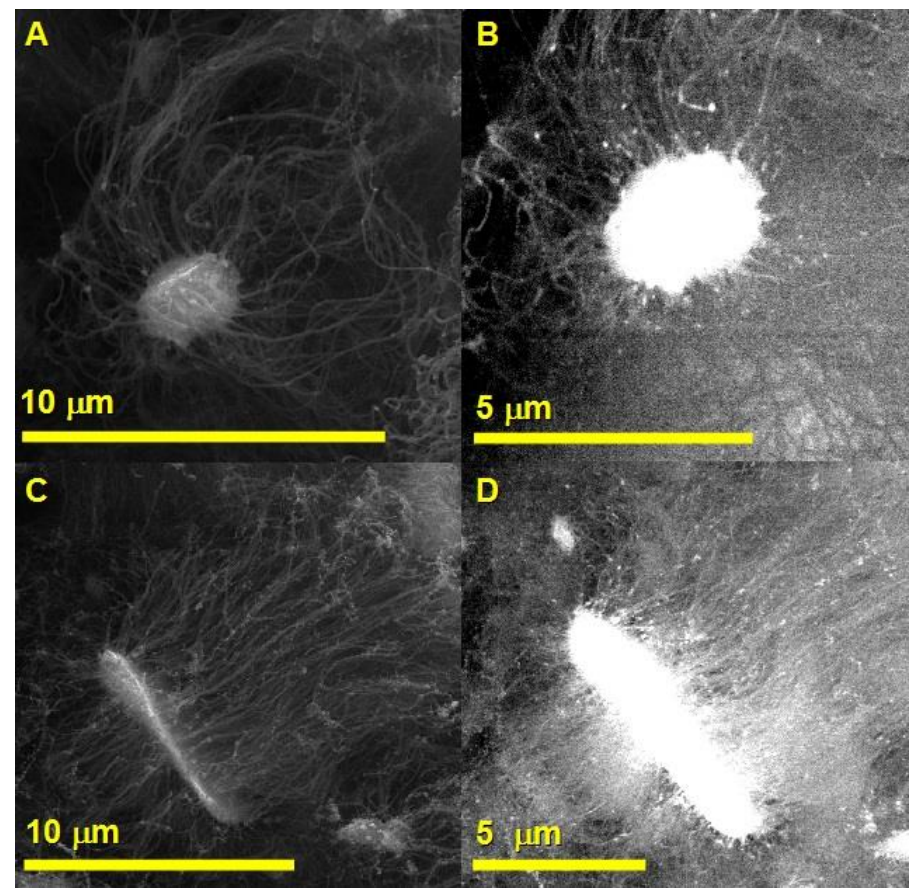

Fig.4 A and C: scanning electron micrographs of individual structures. B and D: backscattered electron micrographs in individual structures. $\mathrm{C}$ and $\mathrm{D}$ are an examples of elongated coreagglomerations, the multiwall carbon nanotubes depart from the flattened faces. 
TEM micrographs revealed the core-agglomeration to be composed of approximately spherical nanoparticles, while the MWCNTs emerge from elongated particles on the periphery of the core, Fig.5. Individual spherical nanoparticles were found to have diameters in the range 500-1000 $\mathrm{nm}$. Energy dispersive X-ray analysis of a low number 5 of spherical particles confirmed the presence of either Ni or FeNi central nanocrystals. In view of the central-agglomeration formation process described above, this is likely to be a consequence of local vapour composition variation in the fluctuating eddies. Similar analysis of the encapsulated nanowires revealed local regions of either $\mathrm{Ni}$ or $\mathrm{FeNi}$, measurement of the spatial extent of these regions requires further work. We speculate that

10 the observed elongation and flattening of the central agglomeration (Figs.4C,D and Fig.6A) is due either i) elongation of the fluctuating eddies due to lowering of the viscosity of the boundary layer through multiple metallocene vapour usage, or ii) there is a micrometre-scale platelet at the centre on which the spherical particles accumulate (this is difficult to quickly confirm by TEM since the beam penetration of the central15 agglomeration is quite low).

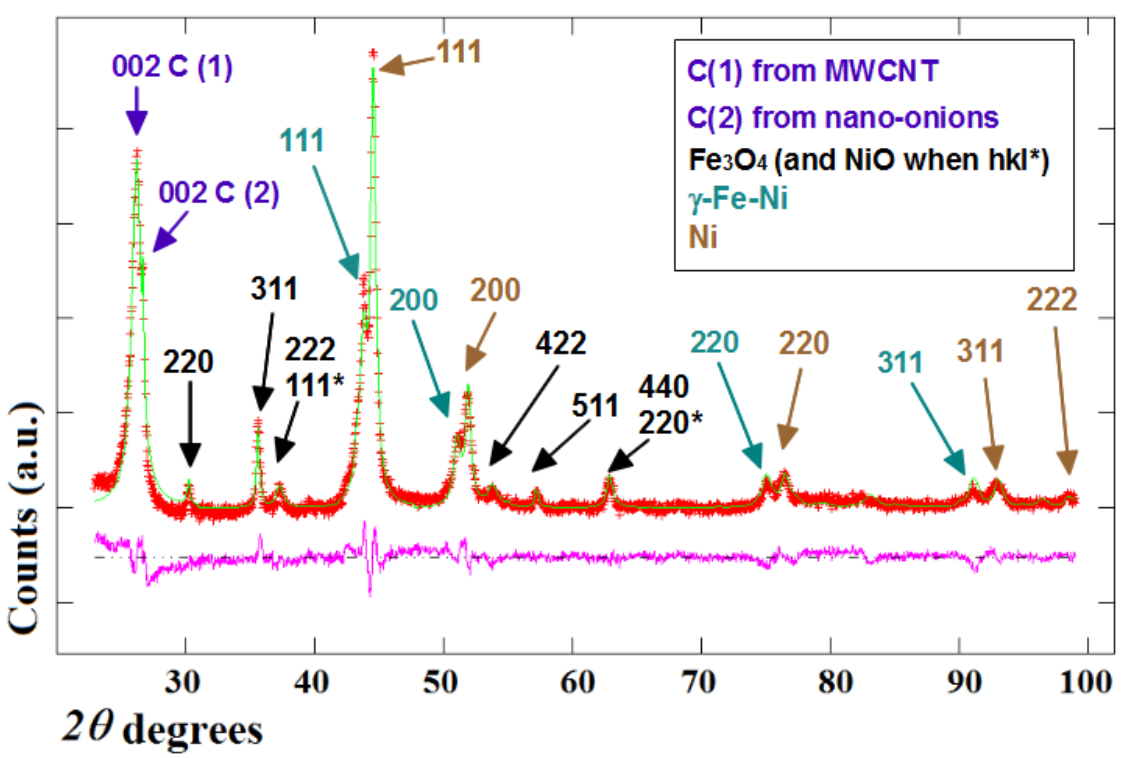

Fig.5 XRD diffractogram (red) and Rietveld refinement (green) from the powder extracted from the reactor. The violet line corresponds to the difference between the diffractogram data and the refinement. The diffraction peaks indicated by the arrows are labelled with the indices of the corresponding crystallographic reflection from the element or compound indicted in the key. $\mathrm{C} 1$ and C2 refers to the two species of graphitic carbon observed on the shell of the encapsulated nanocrystals (here referred to as 'nano-onions') and multiwall carbon nanotubes ${ }^{15}$.

${ }_{25}$ Fig.7 shows the hysteresis loop for a powder sample of the radial structures; the saturation magnetization is $18.5 \mathrm{emu} / \mathrm{g}$ and the coercivity is $500 \mathrm{Oe}$ at $5 \mathrm{~K}$. The latter value is higher than those previously measured for counterpart structures produced by steady-state CVD using dichlorobeneze (90 Oe), trichlorobenzene (415 Oe), and benzene (214 Oe) precursors ${ }^{33,37}$. Similar comparisons of the saturation magnetisation value is difficult since 30 the ferromagnetic oxide and diamagnetic MWCNT contributions are rarely considered. The corrected saturation magnetization value of the ferromagnetic fraction (30\%) of this sample (i.e. the $\gamma$-FeNi, $\mathrm{Ni}, \mathrm{Fe}_{3} \mathrm{O}_{4}, \mathrm{NiO}$ components) was estimated to be $61.7 \mathrm{emu} / \mathrm{g}$ by 
subtracting the diamagnetic contribution of MWCNTs $(-0.7 \mathrm{emu} / \mathrm{g}$ at $50 \mathrm{kOe})$ from the measured value ${ }^{51}$.

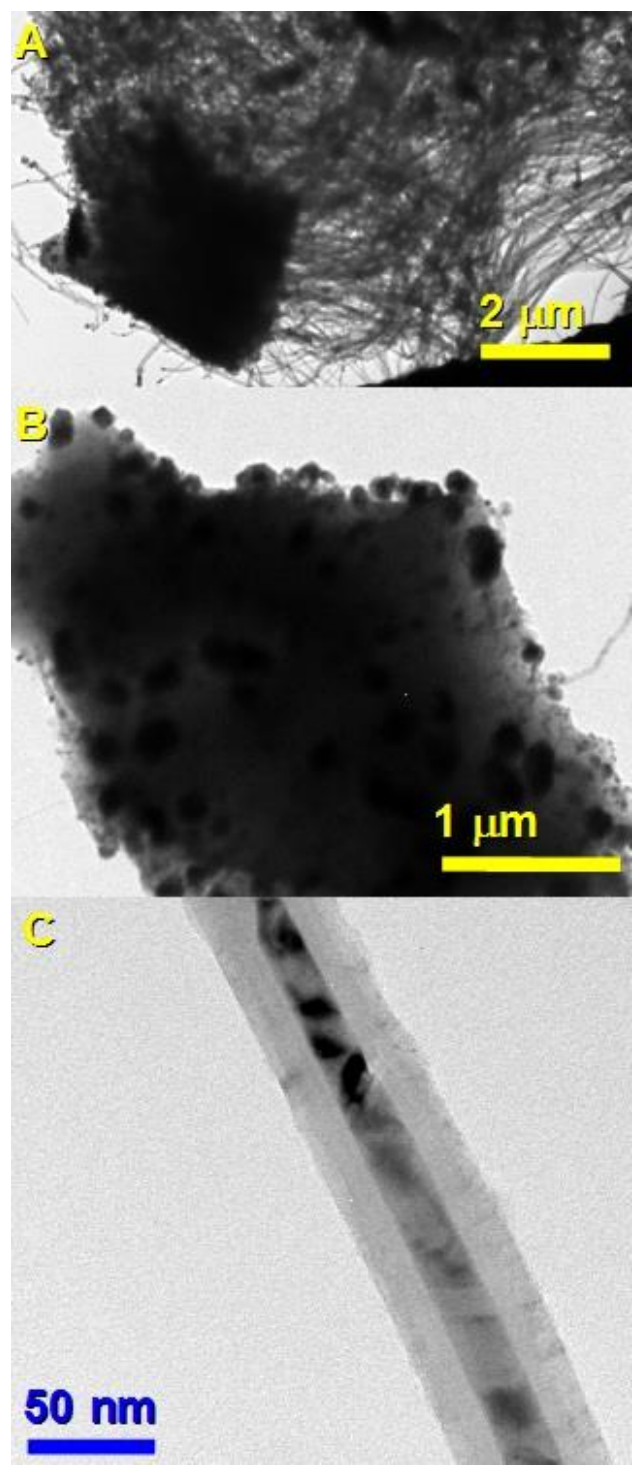

$5 \quad$ Fig.6 Transmission electron micrographs, A; an individual radial structure, B: a detail of a coreagglomeration, $\mathrm{C}$ : detail of a typical MWCNT-encapsulated nanowire. 


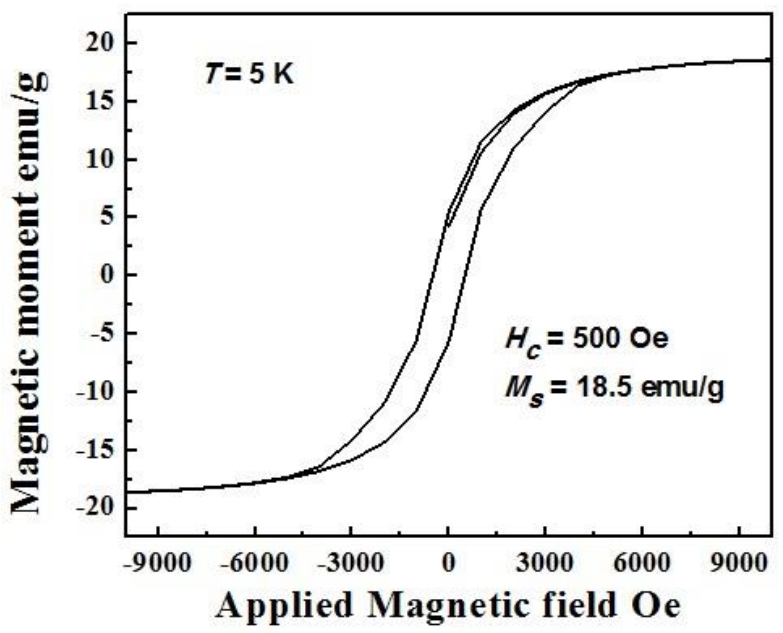

Fig.7 Ferromagnetic hysteresis loop for a powder sample of material extracted from the reactor indicating the coercive field $H_{\mathrm{c}}$, and saturation magnetisation $M_{\mathrm{s}}$.

\section{Conclusion}

Boundary layer chemical vapour synthesis using ferrocene and nickelocene sources was successfully employed to synthesise radial structures comprising ferromagnetic alloy nanowires encapsulated by multiwall carbon nanotubes departing from a central agglomeration. This result is proof that alloying of the encapsulated nanowire is an 10 additional approach to tuning of magnetic properties of these structures.

\section{Acknowledgments}

We acknowledge the financial support from the South-East Physics Network. We also acknowledge Geoff Gannaway and Ken Scott for the help in the preparation of some parts 15 of the reactor, Richard Thorogate for the help in the magnetic measurements and George Nevill for his help in the preparation of the quartz substrates.

\section{References}

${ }^{a}$ School of Physics and Astronomy, Queen Mary University of London, Mile End Road, London E1 $204 N S, U K$.

${ }^{b}$ School of Physical Science and Technology, Sichuan University, Chengdu, 29 Wangjiang Road, 610061 China.

${ }^{c}$ School of Materials Science and Engineering, Queen Mary University of London, Mile End Road, London E1 4NS, UK.

${ }_{25}^{d}$ School of Physical Sciences, University of Kent, Canterbury CT2 7NH, UK.

* Corresponding and presenting author; E-mail:m.baxendale@qmul.ac.uk 
3 J.F. Marco, J.R. Gancedo, A. Hernando, P. Crespo, C. Prados, J.M. González, N. Grobert, M. Terrones, D.R.M. Walton, and H.W. Kroto Hyperfine Interactions 2002, 139-140, 535-542.

4 U. Weissker, S. Hampel, and A. Leonhardt, B. Büchner, Materials 2010, 3, 4387-4427.

5 C. Prados, P. Crespo, J.M. González, A. Hernando, J.F. Marco, R. Gancedo, N. Grobert, M. Terrones, D.R.M. Walton, and H.W. Kroto, Phys. Rev. B 2002, 65, 113405-113409.

6 D. Golberg, M. Mitome, Ch. Müller, C. Tang, A. Leonhardt, and Y. Bando, Acta Materialia. 2006, 54, 2567-2576.

7 C. Müller, D. Golberg, A. Leonhardt, S. Hampel, and B. Büchner, B.. Phys. Stat. Sol. (a) 2006, 203, 1064-1068.

108 U. Weissker, M. Löffler, F. Wolny, M.U. Lutz, N. Scheerbaum, R. Klingeler, T. Gemming, T. Mühl, A. Leonhardt, and B. Büchner, J. Appl. Phys. 2009, 106, 054909-054914.

9 M.U. Lutz, U. Weissker, F. Wolny, C. Müller, M. Löffler, T. Mühl, A. Leonhardt, B. Büchner, and R. Klingeler, J. Phys.: Conf. Ser. 2010, 200, 072062.

10 N. Grobert, W.K. Hsu, Y.Q. Zhu, J.P. Hare, H.W. Kroto, D.R.M. Walton, M. Terrones, H. Terrones, Ph. Redlich, M. Ruhle, R. Escudero, and F. Morales, Appl. Phys. Lett. 1999, 75, 3363 -3365 .

11 R.S. Wagner and W.C. Ellis, Appl. Phys. Lett. 1964, 4, 89-90.

12 A.R. Harutyunyan, O.A. Kuznetsov, C.J. Brooks, E. Mora, and G. Chen, ACS Nano 2009, 3, 37985 .

2013 A. Moisala, A.G. Nasibulin, and E.I. Kauppinen, J. Phys. Condens. Matter. 2003, 15, S3011-35.

14 M. Kumar and Y. Ando, J. Nanosci. Nanotechnol. 2010, 10, 3739-58.

15 F. S. Boi, G. Mountjoy, and M. Baxendale, Carbon 2013, 64, 516-526.

16 B.R. Elliott, J.J. Host, V.P. Dravida, M.H. Teng, and J-H Hwang, J. Mater. Res. 1997, 12, 3328 44.

2517 S. Philippi, U. Weißker, T. Muhl, A. Leonhardt, and B. Buchner, J. Appl. Phys. 2011, 110, 084319.

18 M.U. Lutz, K. Lipert, Y. Krupskaya, S. Bahr, A. Wolter, and A. El-Gendy, Carbon Nanotubes for Biomedical Applications, Springer (Berlin Heidelberg)2011, 97-124.

19 A. Taylor, K. Lipert, K. Kramer, S. Hampel, S. Fussel, and A. Meye, J. Nanosci. Nanotech. 2009, $30 \quad 9,709-16$

20 M.A.A. Elhissi, W. Ahmed, I.U. Hassan, V.R. Dhanak, and A. D’Emanuele, J. Drug Delivery 2012, 2012, 837327.

21 B. Sitharaman and L.J. Wilson, Journal of Nanomedicine, 2006, 1, 291-5.

22 F.Wolny F, Muhl T, Weissker U, Lipert K, Schumann J, and Leonhardt A, Nanotechnology 2010, 21, 435501

23 S. Hudziak, A. Darfeuille, R. Zhang, T. Peijs, G. Mountjoy, G. Bertoni, and M. Baxendale, Nanotechnology 2010, 21, 125505.

24 H. Lin, H. Zhu, H. Guo, and L. Yu, Mater. Lett. 2007, 61, 3547-50.

25 S. Noriaki, N. Masakazu, and K. Takeyuki, Carbon 2007, 45, 78-82.

4026 P.C.P. Watts, W.K. Hsu, V. Kotzeva, and G.Z. Chen, Chem. Phys. Lett. 2002, 366, 42-50.

27 P.C.P. Watts, W.K. Hsu, D.P. Randall, V. Kotzeva, and G.Z. Chen, Chem. Mater. 2002, 14, 4505-8.

28 P.C.P. Watts and W.K. Hsu, Appl. Phys. A, 2004, 78, 79-83.

29 H. Terrones, F. López-Urías, E. Munoz-Sandoval, J.A. Rodríguez-Manzo, A. Zamudio, and A.L.

45 Elías, Theory and Applications. Solid State Sciences 2006, 8, 303-20.

30 R. Lv, S. Tsuge, X. Gui, K. Takai, F. Kang, and T. Enoki, Carbon 2009, 47, 1141-5.

31 N. Grobert, M. Mayne, M. Terrones, J. Sloan, R.E. Dunin-Borkowski, and R. Kamalakaran, Chem. Commun. 2001, 5, 471-2.

32 R. Lv, F. Kang, W. Wang, J. Wei, J. Gu, K. Wang, and D. Wu, Carbon 2007, 45, 1433-8.

5033 R. Lv, F. Kang, D. Cai, C. Wang, J. Gu, K. Wang, and D. Wu , J. Phys. Chem. Sol. 2008, 69, $1213-7$

34 J. Wang, Z. Dong, J. Huang, J. Li, X. Jin, J. Niu, J. Sun, J. Jin, and J. Ma, Appl. Surf. Sci. 2013, 270, 128-2.

35 R. Kozhuharova, M. Ritschel, D. Elefant, A. Graff, I. Monch, T. Muhl, C.M. Schneider, and A.

55 Leonhardt, J. Magetism and Magnetic Mater. 2005, 290-1, 250-3.

36 H. Aurich, A. Baumgartner, F. Freitag, A. Eichler, J. Trbovic, and C. Schonenberger, Appl. Phys. Lett. 2010, 97, 153116.

37 R. Lv, A. Cao, F. Kang, W. Wang, J. Wei, J. Gu, K. Wang, and D. Wu, J. Phys. Chem. C 2007, 111, 11475-9. 
38 N. Grobert, M. Mayne, M. Terrones, J. Sloan, R.E. Dunin-Borkowski, R. Kamalakaran, and T. Seeger, AIP Conference Proceedings 2001, 591, 287.

39 K.L. McNerny, Y. Kim, D.E. Laughlin, and M.E. McHenry, J. Appl. Phys. 2010, 107, 09A312.

40 K.J. Miller, M. Sofman, K. McNerny, and M.E. McHenry, J. Appl. Phys. 2010, 107, 09A305.

541 M.A. Ermakova, D.Y. Ermakov, A.L. Chuvilin, and G.G. Kuvshinov, J. Catalysis 2001, 201, 183-97.

42 C. Muller, D. Golberg, A. Leonhardt, S. Hampel, and B. Buchner, Physica Status Solidi A 2006, 203, 1064-68.

43 S. Groudeva-Zotova, R. Kozhuharova, D. Elefant, T. Muhl, C.M. Schneider, and I. Monch, J.

10 Magnetism and Magnetic Mater. 2006, 306, 40-50.

44 S.A. Moshkalev andC. Verissimo, J. Appl. Phys. 2007, 102, 044303.

45 O.A. Louchev and H. Kanda, J. Chem. Phys. 2004, 121, 446-56.

46 W. Ren, F. Li and H.M. Cheng. J. Phys. Chem B 2006, 110, 16941-6.

47 J.Y. Raty, F. Gygi, and G. Galli, Phys. Rev. Lett. 2005, 95, 096103.

1548 S. Helveg, C. Lopez-Cartes, J. Sehested, P.L. Hansen, B.S. Clausen, J.R. Rostrup-Nielsen, F. Abild-Pedersen, and J.K. Nørskov, Nature 2004, 427, 426-9.

49 A.K. Schaper, H. Hou, A. Greiner, and F. Phillipp, J. Catalysis 2004, 222, 250-4.

50 A. Schneider, Corrosion Science 2002, 44, 2353-65.

51 V. Likodimos, S. Glenis, and N. Guskos, C.L. Lin, Phys. Rev. B 2003, 68, 045417. 